* Pós-Doutora em Direito pela Universidade de Lisboa; Doutora e Mestre em Direito das Relações Sociais pela Pontifícia Universidade Católica de São Paulo (PUCSP); Docente da Universidade Estadual de Maringá (UEM) e no Doutorado e Mestrado do Programa de Pós-Graduação em Ciências Jurídicas pelo Centro Universitário de Maringá (UNICESUMAR); Pesquisadora e Bolsista Produtividade em Pesquisa do Instituto Cesumar de Ciência, Tecnologia e Inovação (ICETI); Advogada no Paraná E-mail: valeria@galdino.adv.br

**Mestranda em Ciências Jurídicas pelo Centro Universitário de Maringá (UNICESUMAR); Pós-Graduada em Direito Público pela Fundação Escola do Ministério Público do Estado do Paraná (FEMPAR); Pós-Graduada em Direito Público pela Escola da Magistratura do Paraná (EMAP); Pós-Graduada em Direito Público pela Universidade Potiguar (UnP); Bacharela em Direito pelo Centro Universitário Curitiba (UNICURITIBA); Tabeliã

E-mail: marianafrancoc@ hotmail.com

\section{Os Direitos da Personalidade no Direito Brasileiro: Do Fenômeno de Personalização À Cláusula Geral de Direito da Personalidade}

\author{
Personality Rights in Brazilian Law: From the \\ Personality Phenomenon to the General Clause of \\ Personality LaW
}

\section{Valéria Silva Galdino Cardin* Mariana Franco Cruz**}

Como citar: CARDIN, Valéria Silva Galdino; CRUZ, Mariana Franco. Os direitos da personalidade no Direito brasileiro: do fenômeno de personalização à cláusula geral de direito da personalidade. Revista do Direito Público, Londrina, v. 15, n. 2, p. 10-26, ago. 2020. DOI: 10.5433/24157-108104-1.2020v15 n2p. 10. ISSN: 1980-511X

Resumo: A consagração dos direitos de personalidade no Código Civil brasileiro de 2002 é consequência de uma série de transformações sociais e jurídicas operadas ao longo dos séculos XIX e XX, que culminaram na concepção de que o novo centro do ordenamento jurídico é a pessoa humana, circunstância que gera um processo de personalização do direito. Com isso, o Direito Civil aos poucos perde o seu caráter eminentemente patrimonialista e passa a ser orientado pela Constituição Federal de 1988. Hodiernamente, os direitos de personalidade estão expressamente previstos a partir do artigo 11 do Código Civil de 2002, entretanto, à luz do neoconstitucionalismo, ainda insta reconhecer o artigo 12 do referido diploma como uma cláusula geral de direito da personalidade. Para tanto, a presente pesquisa utilizou o método teórico, fundamentado na análise e revisão bibliográfica de obras, artigos científicos, doutrina e jurisprudência aplicáveis ao caso.

Palavras-chave: Direitos da personalidade. Dignidade humana. Despatrimonialização. Personalização. Positivação.

Abstract: The implementation of personality rights in the Brazilian Civil Code of 2002 is the result of a series of social and legal transformations throughout the nineteenth and twentieth centuries, culminating in the conception that the new center of the legal order is the human person, a circumstance that personalizes 
law. With this, Civil Law gradually loses its patrimonial characteristic and is guided by the Brazilian Federal Constitution of 1988. In Brazil, article 11 of the Civil Code of 2002 establishes personality rights, however, in light of neoconstitutionalism, article 12 of the code defines personality law's general clause. In this way, this research utilizes the theoretical method, based on the analysis and bibliographical revision of works, scientific articles, legal doctrines and jurisprudence.

Keywords: Personality Rights. Human dignity. Despatrimonialization. Personalization; Positivation. 


\section{INTRODUÇÃO}

O presente artigo tem por escopo demonstrar o ingresso da categoria de direitos de personalidade no ordenamento jurídico brasileiro, o momento jurídico que permitiu tal construção e a sua positivação pelo Código Civil brasileiro de 2002. A temática se faz relevante na medida em que a positivação dos direitos da personalidade inaugura uma nova fase do Direito Civil, denominado de personalização ou despatrimonialização.

O caminho para que os direitos da personalidade passassem a integrar o Direito pátrio foi possível graças ao ambiente jurídico proporcionado pelo surgimento e pela consolidação do Estado Social que, calcado na dignidade da pessoa humana, deu início a um processo de despatrimonialização do Direito Civil. Processo este que se tornou possível em razão da assunção da pessoa como centro do ordenamento jurídico nas cartas constitucionais promulgadas ao redor do mundo após a Segunda Guerra Mundial.

Paralelamente, o foco do Direito Civil, no atendimento desta nova ordem constitucional, passa a ser a proteção do indivíduo, não apenas no campo das relações entre os particulares, mas também nas relações destes com o Estado. Em resposta a esse movimento, de maiores garantias individuais, em que a pessoa assume um papel preponderante em relação ao patrimônio, surge a categoria dos direitos da personalidade.

Com o objetivo de enfrentar o tema, tratar-se-á, primeiramente, da relação entre os direitos de personalidade e a dignidade da pessoa humana, apontando o processo de despatrimonialização ou personalização do Direito Civil e a eleição da pessoa humana como núcleo do ordenamento jurídico. Em seguida, passa-se a uma breve noção acerca dos direitos de personalidade. A par disso, aponta-se a previsão dos direitos de personalidade no Código Civil brasileiro de 2002, onde o artigo 12 figura como verdadeira cláusula geral de tutela da personalidade humana.

Para tanto, foi utilizado o método teórico, fundamentado na análise e revisão bibliográfica de livros, artigos científicos, periódicos, notícias, doutrina e jurisprudência aplicáveis ao caso e pertinentes para a propositura de soluções acerca da temática.

\section{OS DIREITOS DA PERSONALIDADE E A DIGNIDADE DA PESSOA HUMANA}

Ao abordar o tema concernente aos direitos de personalidade, se faz necessário, essencialmente, situar tal questão dentro de um dado panorama histórico, visto que qualquer análise jurídica que não tenha como base a realidade em que se impõe, levando em conta somente aspectos científicos, mostrar-se-á falha, como bem observa Amaral (2003, p. 110-111), é impossível:

Uma perfeita compreensão do fenômeno jurídico, principalmente do Direito Civil, sem recurso à investigação histórica, que permite identificar os fatores que nele vêm influindo, ao longo do seu processo de formação, principalmente os que 
se verificam no seu estágio atual, de significativas mudanças.

Para tanto, procurar-se-á apontar brevemente o modelo ideológico em que se encontrava a sociedade e, consequentemente, o direito vigente, quando da inserção desta categoria de direitos no ordenamento jurídico. Tal premissa se mostra basilar para o desenvolvimento do presente artigo, pois é a partir dela que se poderá corroborar o motivo pelo qual construiu-se a categoria dos direitos de personalidade e o alcance que tais direitos assumem atualmente no direito pátrio.

Deve-se atentar, ainda, para alguns aspectos. Primeiramente, ao falar de direitos de personalidade, é necessário relacioná-los com o direito constitucional, pois como demonstrarse-á, este último representa a base sob a qual se sustentam os primeiros. De outro lado, há que se ter em mente os novos valores que levaram à criação e à concretização desta categoria de direitos, denominada direitos da personalidade. A par desta noção histórica, pode-se então desenvolver a questão da construção de tais direitos como formas de proteção dos valores essenciais da pessoa humana.

\subsection{Os Novos Aspectos do Direito Civil: Despatrimonialização e Personalização}

Enquanto base jurídica do ordenamento de todas as sociedades, o Direito Civil experimentou, desde o seu surgimento, com o Direito Romano, diversas modificações e adaptações frente ao desenvolvimento da sociedade. Como não poderia deixar de ser e, como instrumento voltado a disciplinar as relações travadas pelo homem, sua evolução é constante, desenvolvendo-se à luz das novas realidades criadas pelo homem ${ }^{1}$.

Atualmente $^{2}$, vivencia-se no Direito Civil um momento de superação do modelo ideológico e social e a inauguração de uma nova fase e visão, conforme bem colocado por Moraes (2003, p. 64):

O sistema de Direito Civil vive hoje um momento de profundas incertezas e indefinições. O descompasso existente entre, de um lado, seus conceitos essenciais, a parte fundante de sua dogmática, provenientes do Direito romano e reelaborados pela Pandecteísta, e, de outro, o contexto completamente diferente talvez mesmo oposto - em que tais conceitos permanecem sendo invocados, gera uma verdadeira crise de identidade.

Este rompimento traz consigo uma série de transformações as quais o direito contemporâneo vem procurando se adaptar. Dentre estas alterações, destaca-se como a mais

1 Ihering (2002, p. 30), ilustra como perfeição a evolução constante do direito: "Não podemos deixar de reconhecer que, tal qual a língua, também o direito realiza uma evolução involuntária e inconsciente, ou, para usar a expressão orgânica, que se processa de dentro para fora. “

2 Embora já se decorram dezesseis anos de promulgação do Código Civil de 2002, vivemos quase um século sob a égide do Código Civil de 1916, fundado em valores voltados para a proteção do patrimônio. Ainda que a Constituição Federal de 1988 tenha trazido como fundamento a dignidade da pessoa humana e que o novo Código Civil tenha sido inspirado por esses valores, a modificação prática e a realização efetiva de tais direitos não é automática. É nesse sentido que se emprega a palavra "atualmente". 
significativa, àquela que culminou em um processo de despatrimonialização do Direito Civil.

Para bem compreender tal fenômeno, deve-se ter em mente que a ideologia inspiradora dos códigos civis dos séculos XIX e XX adveio da Revolução Francesa, ou seja, do individualismo jurídico liberal que estabeleceu, dentre outras coisas, a tríade sob a qual se orientou o Direito Civil moderno (liberdade, igualdade e patrimônio) e a dicotomia entre direito privado e direito público. Sintetiza Radbruch (1997, p. 252-253) de forma bastante clara as concepções de direito privado e público sob a perspectiva do Estado Liberal:

Para o liberalismo o direito privado é o coração de toda a vida jurídica e o direito público, pelo contrário, apenas uma leve moldura que deve ser de protecção ao primeiro particularmente ao direito de propriedade. E na verdade, se a declaração dos direitos do homem e do cidadão, de 1789, via na Coroa apenas um poder revogável, delegado pela nação no interesse de todos e não do monarca, via, por outro lado, na propriedade privada, um direito natural, sagrado, inviolável e imprescritível. O soberano absoluto não fazia mais do que ceder o seu lugar no trono ao capital absoluto.

Conforme afirma Amaral (2003, p. 69), a dicotomia entre direito público e privado representou um dos postulados básicos do Estado Liberal, sendo que a separação entre tais ramos de direito correspondia à separação existente também entre os sistemas da política e da economia, com outra característica, a da abstenção do Estado em intervir na segunda.

Portanto, o que se vislumbrava era um Direito Civil que procurava ao máximo se afastar do direito público, sob o argumento de proteção da liberdade do indivíduo, mas cujo objeto era a proteção do patrimônio de forma absoluta. $\mathrm{O}$ fracasso do modelo liberal e o advento do Estado Social romperam com essa estrutura, traçando um novo paradigma para o Direito Civil contemporâneo.

Isso porque o modelo do Estado Social continha valores diversos daqueles que sustentavam o liberalismo. Por óbvio, estas alterações também refletiram no direito, em especial, na distinção existente entre o direito público e o privado, pois, como coloca Radbruch (1997, p. 256), “dentro de uma ordem jurídica de carácter social o direito público e o privado não se acham ao lado um do outro, separados por uma fronteira rigorosa. Pelo contrário, tendem a confundir-se e invadir-se reciprocamente".

Dessa forma, o alicerce do Direito Civil, focado essencialmente no patrimônio, transmuta-se e passa a ter como enfoque a pessoa humana, passando então, da patrimonialização à personalização. Com a despatrimonialização ${ }^{3}$, aduz Perlingieri (2002, p. 33), ocorre uma tendência normativo-cultural em que o ordenamento opta entre o personalismo (a superação do indivíduo) em detrimento do patrimonialismo (a superação da patrimonialidade como fim em si mesma, do positivismo, antes, e do consumismo, depois, como valores).

O Direito Civil, então, abandona o seu caráter patrimonialista e firma-se como um

3 A doutrina, por vezes, se refere ao fenômeno da despatrimonialização com outros termos, como socialização, publicização e humanização. 
"direito personalista ${ }^{4}$, na medida em que tem por objetivo a proteção da pessoa e dos seus interesses de ordem familiar e patrimonial”. (AMARAL, 2003, p. 110). Assim, é de se perceber que esta mudança tão significativa em um dos pilares fundamentais do Direito Civil não se deu de forma repentina, mas resultou de um longo processo em que o mundo passou por intensas modificações sociais e morais, tais como as advindas da Segunda Guerra Mundial e do surgimento do Estado Social de Direito. Segundo Gebran Neto (2002, p. 46):

Desde a Declaração dos Direitos do Homem até o advento da Segunda Guerra Mundial prevaleceu no mundo ocidental uma concepção de Estado liberal, com restrições à ação estatal e um catálogo mínimo de direitos e garantias individuais. Após a Segunda Guerra ocorre uma mudança paradigmática, voltando-se as cartas constitucionais para modelos democráticos e social-democráticos, estabelecendo direitos fundamentais.

Então, com o surgimento do Estado Democrático de Direito, a figura da pessoa humana desloca-se para o centro do ordenamento jurídico e tem-se a consagração do princípio da dignidade da pessoa humana ${ }^{5}$ nas cartas constitucionais advindas do período posterior à Segunda Guerra Mundial. Destaca também Lotufo (2006, p. 25) que as mudanças ocorridas no Direito Civil em razão do fenômeno de redemocratização do mundo após a Segunda Guerra:

Muitas matérias relativas à pessoa humana acenderam, neste período, em nível Constitucional, sendo necessário, portanto, uma ampla reforma de concepção do Direito Civil, bem como uma reestruturação dos Códigos Civis. Surge um descompasso e a necessidade de um novo estudo, o que muitos autores, entre estes, Joaquim Arce Florez-Valdes, na Espanha, Ana Prata, em Portugal, Marc Frangi e Pierre Kayser, na França, Pietro Perlingieri e Antonio Badassare, na Itália, chamaram de Direito Civil Constitucional, pregando a inteligência do Direito Civil tendo como centro não mais o Código Civil, mas a Constituição dos respectivos países.

A partir do momento em que a dignidade da pessoa humana adquire status constitucional e passa a ser o princípio orientador de todo sistema, rompe-se, automaticamente, com toda a estrutura ideológica sob a qual se fundava o Direito Civil que, em decorrência do personalismo, passa a ter como fundamento ideológico, na expressão de Larenz (1978, p. 45), a pessoa humana.

Desta forma, destaca-se que somente a partir do surgimento do Estado Democrático

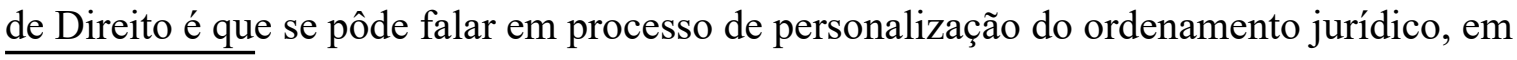

4 Quando se aduz que o Direito Civil assume uma visão personalista deve-se levar em conta que esta visão vai ser assumida em todo o ordenamento jurídico e não apenas no Direito Civil. Isso porque, com o fim da dicotomia entre direito público e privado, o Direito Civil será orientado também de acordo com os valores de direito público trazidos pela Constituição. De outro lado, o fato de o Direito Civil assumir a concepção personalista não significa uma adoção de noção individualista de sociedade e sim a partir de uma noção de pessoa inserida numa comunidade.

5 Claro é o conceito de princípio da dignidade da pessoa humana apontado por Szaniawiski, (2005, p. 143): “O princípio da dignidade da pessoa humana pode ser vislumbrado sob dois aspectos. De um lado, representa uma qualidade substancial do ser humano. A dignidade como sendo a expressão da essência da pessoa humana, e de outro, o fundamento da ordem política e de paz social, revelando-se uma fonte de direitos". 
direitos fundamentais e, posteriormente, em direitos de personalidade. Estes quatro pontos: Estado Democrático de Direito; caráter personalista do direito; direitos fundamentais e direitos de personalidade se inter-relacionam e se pressupõem, o que culmina numa ordem lógica, onde a falta de um dos elementos implica na inexistência do subsequente.

Porquanto, o Estado de Democrático de Direito implica que a pessoa seja tida como centro de todo ordenamento jurídico e que receba uma efetiva tutela de seus direitos, que se traduzem na garantia dos direitos fundamentais do homem. De outro lado, não se pode conceber direitos de personalidade sem que exista uma tutela efetiva dos direitos fundamentais. Também é nesse sentido a posição de Oliveira; Muniz (1979), que visualizam não ser possível a concepção de uma tutela efetiva dos direitos da personalidade desconexa com a proteção dos direitos humanos, uma vez que somente no Estado de Direito esta proteção alcança real concretização.

Conforme Larenz (1978, p. 96), a Constituição passa a ter fundamental importância para a interpretação e para o desenvolvimento do direito privado, à medida que não se limita apenas a regular a organização do Estado, mas também a estabelecer princípios gerais de direito, os quais delimitam a área de atuação de todos os ramos de direito ${ }^{6}$. Em vista disso, há que se ter em mente que as Constituições Democráticas no Estado Social se transformam em fundamento do ordenamento jurídico, o que significa que o Direito Civil passa a ser orientado de acordo com os princípios e os valores elencados nestes documentos.

\subsection{A Pessoa Como Centro do Sistema Jurídico: O Novo Paradigma Do Direito Civil}

Decorre do pensamento da Igreja Social Cristã o pioneirismo com relação à concepção de uma dignidade pessoal, pertencente a cada indivíduo, a qual se desenvolveu na filosofia moderna e se consolidou como atributo de valor absoluto e inerente ao homem ${ }^{7}$. De igual modo é a explicação de Silva (2000, p. 177), quanto ao favorecimento, no pensamento cristão, do desenvolvimento da dignidade da pessoa humana:

O cristianismo primitivo continha uma mensagem de libertação do homem, na sua afirmação da dignidade eminente da pessoa humana, porque o homem é uma criatura formada à imagem de Deus, e esta dignidade pertence a todos os homens sem distinção, o que indica uma igualdade fundamental de natureza entre eles.

Destaca Camargo (2006, p. 46) que a tradição cristã e a filosofia kantiana representam as duas grandes correntes das quais a dignidade retira toda a sua riqueza de conteúdo:

\footnotetext{
6 No original: "La Ley Fundamental no se ha limitado a regular la organización del Estado Federal, sino que contiene, ante todo en la parte relativa a los derechos fundamentales y también en otras secciones, principios jurídicos generales que vinculan a los tribunales como derecho de vigencia inmediata". (LARENZ, 1978, p. 96).

7 O constitucionalista português Canotilho (1996, p. 502) indica o pensamento cristão e o surgimento da noção dos direitos naturais como precursores da ideia que culminou nos direitos fundamentais do homem: "As concepções cristãs medievais, especialmente o direito natural tomista, ao distinguir entre lex divina e lex positiva, abriram o caminho para a necessidade de submeter o direito positivo às normas jurídicas naturais, fundadas na própria natureza dos homens".
} 
A doutrina cristã foi a grande responsável pelo surgimento da noção de dignidade humana no mundo ocidental. Apesar de alguns de seus elementos terem sido formulados pela Escola Estoicista, é no Cristianismo que o conceito de pessoa, como ser dotado de dignidade, encontra suas raízes. Com o surgimento do Iluminismo, no século XVIII, que substituiu a religião pelo homem, colocando-o no centro do sistema de pensamento, destaca-se o pensamento de Immanuel Kant, pioneiro na formulação da concepção moderna de dignidade humana. É na filosofia Kantiana que esta noção encontra seu suporte filosófico fundamental, assim como a sua concepção humanista e universalista.

Tem-se então, que é a modificação do conceito de pessoa, ligado à dignidade, que permitiu ao homem ser colocado no centro de todo pensamento moderno. Para melhor demonstrar tal evolução, é essencial recorrer ao pensamento desenvolvido pelo doutrinador alemão Larenz (1978, p. 44), segundo o qual, a pessoa deve ser entendida como um conceito ético fundamental que se traduz num personalismo ético, sendo este a base ideológica do Código Civil. Leciona o referido autor que:

Esta consideración que el código civil hace del ser humano como persona nacida, por así decirlo, se hace comprensible, junto con todas las consecuencias que de ello se derivan, solamente sobre el fondo de una comprensión del hombre según la cual la condición de persona es cualidad que distingue al hombre sobre todos los demás seres vivientes. Con ello se considera que el hombre, de acordo con su peculiar naturaleza y su destino, está constituido para configurar libre y responsablemente su existencia y su entorno en el marco de las posibilidades dadas en cada caso, para proponerse objetivos e imponerse a sí mismo límites en su actuación (LARENZ, 1978, p. 45).

Esta noção de homem, continua Larenz (1978, p. 46), decorre da manifestação do personalismo ético enunciado por Kant, onde o homem, enquanto fim em si mesmo, representa um imperativo ético fundamental do ordenamento:

Los seres irracionales tienen solamente un valor relativo, como medios y, por ello, se llaman cosas; en cambio, los seres racionales son llamados personas, pues su naturaleza les distingue ya como fines en sí mismos, esto es, algo que no está permitido. De ello se sigue que todo ser humano tiene frente a cualquier otro el derecho de ser respetado por él como persona, a no ser perjudicado en su existencia (la vida, el corpo, la salud) y en un ámbito propio del mismo y que cada individuo está obligado frente a cualquier otro de modo análogo.

Assenta ainda Larenz (1978) que o personalismo ético atribuí ao homem, precisamente porque é pessoa, um sentido ético, um valor em si mesmo, não simplesmente como meio para outros fins, e, neste sentido, uma dignidade. De tal modo, o ser humano, exatamente porque é pessoa, possui dignidade, sendo esta a característica que o distingue de todos os demais seres irracionais. Como o direito é voltado para homem e este possui como característica distintiva 
a qualidade de ser pessoa, deve o direito se orientar para garantir a sua dignidade, sendo este o fundamento ideológico de todo o sistema jurídico.

Tendo como base essa ideia de pessoa é que as Constituições dos Estados Democráticos começaram a estabelecer os direitos fundamentais do homem, dentre os quais se encontra o da dignidade da pessoa humana. ${ }^{8}$ Considerando que Direito Civil, até o advento destas cartas constitucionais, tinha como fundamento ideológico a proteção do indivíduo (e não da coletividade), sob uma ótica patrimonial, viu-se a necessidade da releitura deste ramo do direito, fato que culminou no processo de constitucionalização do Direito Civil. (CANOTILHO, 1996). Tal processo representa a superação da dicotomia entre o direito público e o privado, pois a aplicação de ambos é orientada para o mesmo fim: a proteção da dignidade da pessoa humana. Nesse sentido, postula Lorenzetti (1998, p. 253) que:

A Constituição tem disposições de conteúdo civilista aplicáveis ao âmbito privado. Igualmente, tem em seu seio as normas fundamentais da comunidade, a sua forma de organizar-se, às quais se remete permanentemente o Direito Privado. De outro ponto de vista, o Direito Privado é Direito Constitucional aplicado, pois nele se detecta o projeto de vida em comum que a Constituição tenta impor, o Direito Privado representa os valores sociais de vigência efetiva.

Perlingieri (2002, p. 45), segue o mesmo raciocínio:

O Direito Civil não se apresenta em antítese ao Direito Público, mas é apenas um ramo que justifica por razões didáticas e sistemáticas, e que recolhe e evidencia os institutos atinentes com a estrutura da sociedade, com a vida dos cidadãos como titulares de direitos civis. Retorna-se às origens do Direito Civil como direito dos cidadãos, titulares de direitos frente ao Estado. Neste enfoque, não existe contraposição entre privado e público, na medida em que o Direito Civil faz parte de um ordenamento unitário.

A partir desta nova visão, em que o Direito Civil e direito público, obrigatoriamente, se inter-relacionam, é que irá se desenvolver a teoria relativa aos direitos de personalidade, tendo como plano de fundo a dignidade da pessoa humana.

\section{DA POSITIVAÇÃO DOS DIREITOS DA PERSONALIDADE NO DIREITO BRASILEIRO}

\subsection{Breve Noção Acerca dos Direitos da Personalidade}

\footnotetext{
8 Oportuno colocar a relação existente entre os direitos fundamentais e a dignidade da pessoa humana, como aponta Camargo (2006): "É indiscutível a existência de uma relação de dependência entre a dignidade da pessoa humana e os direitos fundamentais. Ao mesmo tempo em que os direitos fundamentais surgiram como uma exigência da dignidade de proporcionar um pleno desenvolvimento da pessoa humana, é certo também que somente através da existência desses direitos a dignidade poderá ser respeitada, protegida e promovida. Por esta razão, a exigência de cumprimento e promoção dos direitos fundamentais, encontra-se estritamente vinculada ao respeito à dignidade da pessoa humana".
} 
Ao abordar o tema atinente aos direitos de personalidade é de se colocar, conforme apontado por Tepedino (2004), que tal categoria de direitos é fruto de elaboração teórica originária das doutrinas francesa e germânica da segunda metade do século XIX, ou seja, é categoria jurídica relativamente recente. Em razão disso, perdura ainda uma grande dificuldade em se estabelecer um conceito uníssono de tal categoria de direitos, visto que subsistem discussões quanto à natureza de tais direitos e mesmo quanto ao seu alcance.

Diante da necessidade de procurar traçar uma noção dos direitos de personalidade, temse que atentar para alguns aspectos. $O$ primeiro deles refere-se à abrangência que o conceito de personalidade humana assume em nosso sistema jurídico e, o segundo, de que os direitos de personalidade visam garantir a sua tutela. Quando se fala em personalidade no âmbito do direito, deve-se levar em conta as acepções que podem assumir tal termo.

De tal modo, num primeiro momento, o termo "personalidade" traduz-se na possibilidade de a pessoa ser sujeito de direito, ou seja, de ser titular de direitos e obrigações. A personalidade aqui equivale à capacidade, onde a pessoa figura como o elemento subjetivo das situações jurídicas. De outro lado, a personalidade deve ser entendida como o "conjunto de características e de atributos da pessoa humana" (TEPEDINO, 2004, p. 41) e, nesse sentido, a personalidade não pode ser vista como um direito, mas como um valor fundamental do ordenamento. No entender de Dantas (1979 apud TEPEDINO, 2004, p. 28):

Quando falamos em direito de personalidade, não estamos identificando aí a personalidade com a capacidade de ter direitos e obrigações; estamos então considerando a personalidade como um fato natural, como um conjunto de atributos inerentes á condição humana; estamos pensando num homem vivo e não nesse atributo especial do homem vivo, que é a capacidade jurídica em outras ocasiões identificado como a personalidade.

Os direitos de personalidade visam proteger a personalidade em sua segunda acepção, ou seja, como valor, onde a pessoa não representa apenas o elemento subjetivo da relação jurídica, mas também o seu elemento objetivo, conforme defende Perlingieri (2002, p. 155):

A esta matéria não se pode aplicar o direito subjetivo elaborado sobre a categoria do "ter". Na categoria do "ser" não existe a dualidade entre sujeito e objeto, porque ambos representam o ser, e a titularidade é institucional, orgânica. Onde o objeto da tutela é a pessoa, a perspectiva deve mudar, torna-se necessidade lógica reconhecer, pela especial natureza do interesse protegido, que é justamente a pessoa a constituir ao mesmo tempo o sujeito titular do direito e o ponto de referência objetivo de relação.

Destarte, a noção de personalidade que enseja proteção é justamente àquela em que esta é vista como um valor que decorre do próprio ser humano, como sintetiza Amaral (2003, p. 141):

A personalidade é, então, o instituto básico do Direito Civil, e a pessoa, o seu núcleo fundamental. $\mathrm{O}$ direito protege-a e garante-lhe a reprodução e a 
conservação, por meio dos direitos de personalidade, do direito de família e do direito patrimonial. $\mathrm{O}$ instituto da personalidade, compreende, assim, as normas sobre o princípio e o fim da existência, qualificação e exercício dos direitos das pessoas físicas e jurídicas.

A par da noção de personalidade, pode-se, então, partir para a busca de uma definição dos direitos relativos à mesma. Portanto, os direitos de personalidade abrangem os direitos que são considerados essenciais à pessoa humana, no que se refere a sua dignidade, ou dito de outra forma, os direitos de personalidade são aqueles que visam tutelar os atributos decorrentes da personalidade enquanto valor. Quanto ao alcance dos direitos de personalidade, discorre De Cupis (2004, p. 24):

Existem certos direitos sem os quais a personalidade restaria uma susceptibilidade completamente irrealizada, privada de todo o valor concreto: direitos sem os quais todos os outros direitos subjetivos perderiam todo o interesse pelo indivíduo - o que equivale dizer que se eles não existissem, a pessoa não existiria como tal. São esses os chamados direitos essenciais, com os quais se identificam precisamente os direitos de personalidade.

Por sua vez, Gomes (1997, p. 151), relata a dificuldade de estabelecer um conceito acerca dos direitos de personalidade, afirmando que tal definição deve levar em conta o objeto de tais direitos:

A diversidade dos conceitos na doutrina atesta a dificuldade de formulação, agravada pela circunstância de ser heterogênea a categoria dos direitos de personalidade e convertida sua fundamentação. Noção mais clara obtém-se mediante delimitação de seu objeto em termos perfeitamente admissíveis. Constituem-no os bens jurídicos em que se convertem projeções física ou psíquicas da pessoa humana, por determinação legal que os individualiza para lhes dispensar proteção.

Para Rodrigues (2003, p. 61), direitos de personalidade são àqueles "inerentes à pessoa humana e, portanto, a ela ligados de maneira perpétua e permanente", não podendo existir um ser humano sem direito à vida, por exemplo. Já Pereira (1999, p. 152), aduz que, a par dos direitos economicamente apreciáveis, outros há, não menos valiosos, merecedores de amparo e proteção da ordem jurídica atinente à própria natureza humana.

Certo é que os conceitos apresentados pela doutrina se assemelham na medida que colocam os direitos de personalidade como direitos que visam tutelar a pessoa humana no que se refere a seus atributos. Atributos estes que decorrem da personalidade entendida como valor, onde o objeto e o sujeito de tais direitos residem na própria pessoa. ${ }^{9}$

9 Gomes (1997, p. 151) discorda desta visão em que o sujeito e o objeto dos direitos de personalidade se confundem e residem na própria pessoa. Afirma o referido autor "Não é a personalidade, por outro lado, objeto desses direitos, visto que, sendo o pressuposto de todos os direitos, em si mesma não é um direito e muito menos objeto de qualquer relação". Para o autor, o objeto desses direitos seria constituído de bens jurídicos, os quais seriam énunciados pela lei, e que não se confundiriam com a personalidade, que jamais poderia ser objetos desses direitos. É de se observar que a posição de Orlando Gomes foi calcada sob a ótica patrimonialista do Direito Civil, onde o objeto da relação 


\subsection{Os Direitos Da Personalidade No Código Civil De 2002}

\section{O Código Civil brasileiro de 1916 não previa expressamente os direitos de} personalidade e tão somente lançava alguns meios indiretos de proteção de direitos relativos à pessoa humana. Já o Código Civil de $2002^{10}$, construído sob uma ótica distinta do anterior, representou um grande avanço no que se refere à tutela da personalidade humana, ao contemplar um capítulo próprio para tratar dos direitos de personalidade, o Capítulo II, do Livro I, da Parte Geral, composto pelos artigos 11 a 21. Neste contexto, Doneda (2003, p. 35), destaca a importância dessa inovação no Código Civil de 2002:

O Código Civil brasileiro dedica todo um capítulo aos direitos de personalidade, categoria à qual o legislador se refere pela primeira vez. Sua posição, na parte geral do código, reflete uma mudança paradigmática do Direito Civil, que se reconhece como parte de um ordenamento cujo valor máximo é a proteção da pessoa humana. A esta constatação segue uma reelaboração da dogmática civilista, na qual os direitos de personalidade desempenham importantíssimo papel fundamental.

Pinto (2003, p. 8) também se refere à inovação do Código Civil brasileiro, como algo que deve ser saudado, acentuando sua relevância em face do texto constitucional:

A consagração no Código Civil desses direitos marca, com a chancela do legislador, o acolhimento e a recepção dos "direitos do Homem" no diploma fundamental do direito privado. Estes, que já eram direitos fundamentais perante o poder público - reconhecidos, pelo menos, desde a época das grandes declarações de direitos e, se estendiam também às relações privadas por força das próprias disposições constitucionais que os consagravam, passam agora a ter, consagrado na lei, um "equivalente" civilístico, através do qual se haverá de processar, em primeira linha, a recepção e a atuação das correspondentes valorações constitucionais neste domínio.

No Código Civil brasileiro, os direitos de personalidade podem ser divididos em dois grupos: em tutela geral de personalidade ${ }^{11}$, constante do art. $12^{12}$ e direitos especiais de

jurídica deveria representar necessariamente um bem jurídico externo à pessoa humana. Segundo Tepedino (2004), esta visão não mais se justifica e consolidado está o fato de que os direitos de personalidade têm por objeto a própria pessoa do sujeito.

10 Lotufo (2006, p. 28) destaca a ideologia que inspirou o Código Civil de 2002, tornando-o Código aberto e fundado no indivíduo e na coletividade: "Este Código, pelas suas próprias raízes metodológicas e filosóficas, não tem a aspiração de ser um Código fechado. É um Código que está embutido do que o professor Miguel Reale chamou de princípio da socialidade, ou seja, todos os valores do Código encontram um balanço entre o valor do indivíduo e da sociedade. Não exacerba o social e, ao mesmo tempo, procura em todas as regras não exacerbar o individualismo".

11 Oportuna é a definição de Larenz (1978, p. 161) quanto ao direito geral de personalidade: "Ha de entenderse por derecho geral de la personalidad el derecho al respeto, a la no lesión de la persona en todas sus manifestaciones inmediatas dignas de protección (tales como lo declarado oralmente o escrito por la misma) y en la esfera privada e íntima, substraída a la curiosidad y a la inoportunidad de otros sin que con ello se dé ya una delimitación terminante y segura".

12 Embora a maioria dos autores entenda que a cláusula geral de personalidade no Código Civil brasileiro seja representada apenas pelo art. 12, Tepedino (2004) coloca que o art. 21 também é uma cláusula geral de personalidade. 
personalidade, dos artigos 13 a 21, onde se encontram algumas tipificações específicas de alguns desses direitos. Especial atenção deve ser dada quando da interpretação do art. 12, que prevê a possibilidade de cessão de ameaça ou de lesão à direito de personalidade. Tal artigo teve como inspiração o art. 70 do Código Civil português ${ }^{13}$, que prevê, expressamente, uma cláusula geral de tutela da personalidade humana ${ }^{14}$. Assim, o art. 12 se constituiria, também, em uma cláusula geral de tutela da personalidade humana.

Contudo, a doutrina brasileira diverge quanto a esta questão. Enquanto alguns autores entendem que o art. 12 constitui-se em cláusula geral de personalidade, outros apontam que o referido artigo não conseguiu atingir o alcance constante do art. 70 do Código Civil português, não podendo, então, ser entendido como cláusula geral de tutela da personalidade humana.

$\mathrm{Na}$ esteira daqueles que defendem o art. 12 do Código Civil brasileiro como cláusula geral de personalidade estão Tepedino (2004, p. 36) e Szaniawiski (2005, p. 179). Para os autores, a leitura do referido artigo não pode ser feita de maneira isolada, apenas à luz do Código Civil, e em cotejo com a Carta Constitucional de 1988, pois é onde reside o seu fundamento: o princípio da dignidade da pessoa humana. Dessa forma, a partir de uma leitura civilconstitucional, o art. 12 do Código Civil brasileiro de 2002 representaria uma cláusula geral infraconstitucional de tutela da personalidade humana.

Como assevera Tepedino (2004, p. 37):

Ambos dispositivos (artigos 12 e 21), lidos isoladamente no âmbito do corpo codificado, não trazem grande novidade, sendo certo que a vida privada é constitucionalmente inviolável e que qualquer lesão ou ameaça de lesão possibilita a correspondente tutela jurisdicional. Os preceitos ganham, contudo, algum significado se interpretados como especificação analítica da cláusula geral de tutela da personalidade prevista no Texto Constitucional nos arts. $1^{\circ}$, III (a dignidade humana como valor fundamental da República), $3^{\circ}$, III (igualdade substancial) e $5^{\circ}, \S 2^{\circ}$ (mecanismo de expansão do rol de direitos fundamentais). A partir daí, deverá o intérprete romper com a ótica tipificadora do Código Civil, ampliando a tutela da pessoa humana não apenas no sentido de admitir uma ampliação de hipóteses de ressarcimento mas, de maneira muito mais ampla, no intuito de promover a tutela da personalidade mesmo fora do rol de direitos subjetivos previstos pelo legislador codificado.

13 Quanto à influência do Código Civil português, destaca Pinto (2003, p. 7): "Um primeiro aspecto em que é flagrante a aproximação entre ambos os diplomas é o que respeita a localização das normas sobre direitos de personalidade no sistema do Código. A matéria encontra-se no Código Civil brasileiro logo nos artigos 11 a 21, no Capítulo II, do Título I (Pessoas naturais) da Parte Geral. Em Portugal, a localização é a correspondente à secção II do capítulo do Código Civil português relativo às pessoas singulares da Parte Geral (dentro do subtítulo relativo às pessoas e do título da relação jurídica). É igualmente patente que as opções do legislador brasileiro se aproximaram muito do Código português quanto à extensão e, mesmo, à estrutura da regulamentação. Assim, ambos os Códigos dedicam um número aproximado de artigos ao tema (onze artigos no Código brasileiro - artigos 11 a 21 - e doze no Código português - artigos 70 a 81). Além disso, ambos os diplomas se limitam a regular aspectos comuns aos direitos de personalidade, e, apenas, alguns direitos de personalidade em especial, em relação aos quais se entendeu que havia pontos a necessitar do esclarecimento legislativo."

14 Quanto a questão coloca Sousa (1995, p. 104): “O vigente Código Civil português incorpora no art. 70. ${ }^{\circ}$ uma cláusula geral de tutela geral de personalidade humana, pela qual a lei protege os indivíduos contra qualquer ofensa ilícita ou ameaça de ofensa à sua personalidade física e moral”. 
De outro lado, Pinto (2003, p. 15), pontua que o Código Civil brasileiro se distancia do Código Civil português exatamente porque não consagrou um direito geral de personalidade:

Uma diferença que chama imediatamente a atenção entre as disciplinas de ambos os Códigos reside, na verdade, no facto de o Código Civil Brasileiro não ter consagrado expressamente uma cláusula de proteção ou "tutela geral da personalidade" [...]. Enquanto o Código Civil Português abre o regime dos direitos de personalidade através desta previsão de uma "tutela geral de personalidade", o Código Civil Brasileiro refere-se, pois, logo a "direitos de personalidade".

Segundo o autor retro, a previsão constante no art. 12 do diploma brasileiro não contém a indeterminação necessária para prever uma fundamentação positiva do direito geral de personalidade. Todavia, assegura que o direito brasileiro permite a complementação, no que se refere à proteção dos direitos de personalidade, por outros ramos do direito, e até mesmo, por construções doutrinárias e jurisprudenciais, como ocorre no direito português. Sendo que esta complementação se dá a partir da concepção de personalidade como valor (PINTO, 2003, p. 15).

Portanto, é de se concluir que a falta de consagração de um direito geral de personalidade no ordenamento pátrio não significa uma falha que não possa ser remediada através de outros mecanismos, não prejudicando a proteção efetiva de tais direitos. Dessa forma, a existência ou não de um direito geral de personalidade no Código Civil brasileiro não implica em um desamparo do nosso direito com relação à proteção da personalidade humana no âmbito do Direito Civil.

Pelo contrário, como a interpretação dos artigos constantes do Código Civil tem que ser feita de acordo com os princípios da Constituição, pode-se dizer que a consagração de tais direitos representa a introdução de comandos normativos abertos, o que era impensável no Código anterior, por força do ideal positivista em que fora construído.

Com isto, o legislador possibilita uma ampla proteção à personalidade humana, pois a abertura de tais comandos permite que eles sejam aplicados no decorrer do tempo, disciplinando as possíveis novas situações que poderão surgir sem que se tenha um esvaziamento dos mesmos. Acima disso, é forçoso mencionar que se entende como presente no direito brasileiro uma cláusula geral de personalidade consagrada no art. 12 do Código Civil.

\section{CONCLUSÃO}

Com o presente artigo pretendeu-se demonstrar o panorama jurídico-histórico que permitiu a inserção dos direitos de personalidade no Código Civil brasileiro de 2002. Entendese que a compreensão desse panorama é de grande valia não apenas no trato dos direitos de personalidade, mas também para a compreensão dos valores que passaram a sustentar o movimento que culminou no fenômeno da constitucionalização do direito.

A Constituição Federal de 1988 representou a ruptura com o Estado Liberal para a 
assunção do Estado Social, onde o indivíduo e, não mais o patrimônio, passou a ocupar o centro do ordenamento jurídico. Em consequência disso, as normas constitucionais passaram a ocupar o lugar das normas civilistas na regulação das relações sociais, sejam essas relações entre indivíduos ou entre os indivíduos e o Estado.

Nesse contexto, desaparece a dicotomia entre direito público e privado, na medida em que todas as relações devem obediência estrita à Constituição Federal que, por sua vez, tem como fundamento a tutela e a preservação da dignidade humana. Logo, a repersonalização do direito exigiu uma nova resposta do Direito Civil e a positivação expressa dos direitos de personalidade no Código Civil de 2002 é decorrente deste fenômeno.

Entender a relação entre os direitos de personalidade, a dignidade da pessoa humana, a pessoa e a Constituição é compreender muito do que o direito brasileiro disciplina e tem como importante. Concomitantemente, esse entendimento é também revelador dos valores que a atual sociedade quer proteger e resguardar e, como procurou-se demonstrar, a positivação dos direitos de personalidade é resultado de uma grande transformação jurídica (deslocamento do Código Civil do centro do ordenamento jurídico), como também social (surgimento do Estado Social em detrimento do Estado Liberal).

Evidentemente que com grandes transformações surgem a todo momento novos desafios. Assentados os direitos de personalidade, hodiernamente é premente a necessidade de garantir uma real efetividade a esses direitos. Assim, fundamental é o abandono de conceitos normativos quanto à pessoa, de forma a se adotar um conceito substantivo de pessoa, baseado no alcance dos direitos da personalidade.

Essas discussões fogem ao tema deste artigo, porém se faz necessário citá-las, na medida que a efetividade dos direitos de personalidade é o mais importante passo para a garantia real da dignidade humana. Visto que os fundamentos de tais direitos já estão consagrados, cabe agora aos operadores de direito utilizar esses instrumentos para promover uma proteção real desses direitos, visando garantir ou, ao menos, não impedir, que a todos seja assegurado o livre desenvolvimento da personalidade.

\section{REFERÊNCIAS}

AMARAL, Francisco. Direito civil: introdução. 5. ed. Rio de Janeiro: Renovar, 2003.

BRASIL. Lei n⿳ 10.406, de 10 de janeiro de 2002. Institui o Código Civil. Brasília, DF: Presidência da República, [2018]. Disponível em: http://www.planalto.gov.br/ccivil_03/ Leis/2002/L10406.htm. Acesso em: 10 jun. 2019.

CAMARGO, Marcelo Novelino. O conteúdo jurídico da dignidade da pessoa humana. In: CAMARGO, Marcelo Novelino (org.). Leituras complementares de direitos constitucional. 
Salvador: JusPODIVM, 2006. p. 45-65.

CANOTILHO, José Joaquim Gomes. Direito constitucional. 6. ed. Coimbra: Livraria Almedina, 1996.

DE CUPIS, Adriano. Os direitos da personalidade. Campinas: Romana Jurídica, 2004.

DONEDA, Danilo. Os direitos da personalidade no novo código civil. In: TEPEDINO, Gustavo (coord.). A parte geral do novo código civil: estudos na perspectiva civil-constitucional. 2. ed. Rio de Janeiro: Renovar, 2003. p. 35-59.

GEBRAN NETO, João Pedro. A aplicação imediata dos direitos e garantias individuais: a busca de uma exegese emancipatória. São Paulo: Revista dos Tribunais, 2002.

GOMES, Orlando. Introdução ao Direito Civil. 12. ed. Rio de Janeiro: Forense, 1997.

IHERING, Rudolf von. A luta pelo direito. São Paulo: Martin Claret, 2002.

LARENZ, Karl. Derecho civil: parte general. Madrid: Editoriales de Derecho Reunidas, 1978.

LORENZETTI, Ricardo Luis. Fundamentos do direito privado. São Paulo: Revista dos Tribunais, 1998.

LOTUFO, Renan. Da oportunidade da codificação civil e a constituição. In: SARLET, Ingo Wolfgang (org.). O novo código civil e a constituição. 2. ed. Porto Alegre: Livraria do Advogado, 2006. p. 25-26.

MORAES, Maria Celina Bodin de. Danos à pessoa humana: uma leitura civil constitucional dos danos morais. Rio de Janeiro: Renovar, 2003.

OLIVEIRA, José Lamartine Correa de Oliveira; MUNIZ, Francisco José Ferreira. O estado de direito e os direitos da personalidade. Biblioteca Digital de Periódicos, Curitiba, v. 19, 1979. Disponível em: https://revistas.ufpr.br/direito/article/view/8833/6143. Acesso em: 18 jul. 2019.

PEREIRA, Cáio Mário da Silva. Instituições de direito civil. 19. ed. Rio de Janeiro: Forense, 1999.

PERLINGIERI, Pietro. Perfis do direito civil. 2. ed. Rio de Janeiro: Renovar, 2002.

PINTO, Paulo Mota. Direitos de personalidade no código civil português e no novo código civil brasileiro. Revista Jurídica, São Paulo, ano 51, n. 314, p.7-35, dez. 2003.

RADBRUCH, Gustav. A filosofia do direito. 6. ed. Coimbra: Armênio Amado Editor Sucessor, 1997.

RODRIGUES, Silvio. Direito Civil: parte geral. 34. ed. São Paulo: Saraiva, 2003.

SILVA, José. Afonso da. Curso de direito constitucional positivo. 18. ed. São Paulo: Malheiros, 2000.

SOUSA, Rabindranath Valentino Aleixo Capelo de. O direito geral de personalidade. Coimbra: Coimbra, 1995. 
SZANIAWISKI, Elimar. Direitos da personalidade e sua tutela. 2. ed. São Paulo: Revista dos Tribunais, 2005.

TEPEDINO, Gustavo.Temas de direito civil. 3. ed. Rio de Janeiro: Renovar, 2004. 583 p.

Como citar: CARDIN, Valéria Silva Galdino; CRUZ, Mariana Franco. Os direitos da personalidade no Direito brasileiro: do fenômeno de personalização à cláusula geral de direito da personalidade. Revista do Direito Público, Londrina, v. 15, n. 2, p. 10-26, ago. 2020. DOI: 10.5433/24157-108104-1.2020v15n2p. 10. ISSN: 1980-511X

Recebido em: 19/06/2019

Aprovado em: 17/02/2020 